environmental conservation. There shall be a Jury to decide upon the Award, who shall recognize efforts in protecting, improving, and sustaining, our natural resources and environmental heritage.

The schoolchildren who devotedly strive, year in and year out, to preserve and enhance the environmental heritage which forms our life-support system, deserve the gratitude, appreciation, and encouragement of the Society. Those children by their nature do not aim at a reward; but
INSONA believes that, by so drawing attention to their accomplishments, many more children will be inspired to serve the environmental cause.

G.M. OzA, FLS, General Secretary of INSONA
clo Maharaja Fatehsingh Zoo Trust
Indumati Mahal
Jawaharlal Nehru Marg
Baroda 390001 , India.

\title{
CFC Responsibility Claimed for Stratospheric Ozone Depletion*
}

A NASA-WMO sponsored study concludes that (1) ozone has measurably decreased between 1969 and 1986 in mid- and high-latitudes of the northern hemisphere, and (2) the CFCs are most probably responsible for the Antarctic ozone 'hole'. Ozone in the Earth's atmosphere, expecially the 'ozone layer' or shield high in the stratosphere, protects Man and other living things from damaging amounts of ultraviolet radiation from the Sun. Such radiation in excessive amounts causes skin-cancer in humans and can have very serious adverse effects on plants and animals.

In 1985, large unanticipated spring-time ozone losses over Antarctica during the previous decade were reported for the first time in the British journal Nature (London). Since then the compelling scientific questions have been:

A. Have these losses persisted?

B. What is their cause?

C. Is such depletion happening elsewhere on the globe?

In October 1986, an intense scientific effort was started, led by NASA, with the sponsorship of WMO and participation by UNEP and several US Government agencies, to address these questions. Over one-hundred scientists from ten countries formed study-groups, carefully analysing available data and critically debating possible sources of errors in the measurements. A series of computer calculations was also performed to aid in the interpretation of the results of the analyses.

Long-term records, some of which date back to $1957, \dagger$ used in the effort, have been collected by WMO through its Global Ozone Observing System. Satellite observations since 1978 were also used extensively in the study. The scientists' answers to the three questions are that:

A. The annual spring-time stratospheric ozone depletion over in the Antarctic has persisted and deepened;

B. The probable cause of the Antarctic ozone hole is Man-made chlorine pollutants especially chlorofluorocarbons (CFCs); and

C. Long-term data records show ozone decrease in the mid- and high-latitudes of the northern hemisphere.

The key findings of the study are given in the following sixteen numbered paragraphs:

\section{Source and Trace Gases}

1) There is undisputed observational evidence that the atmospheric concentrations of source-gases which are important in controlling stratospheric ozone levels (chlorofluorocarbons, halons, methane, nitrous oxide, and carbon dioxide) continue to increase on a global scale because of human activities.

\footnotetext{
* Based on the Executive Summary of the International Ozone Trends Panel.-Ed.

$\dagger$ and even, we have long understood, to the 1920s at Oxford, England, and soon thereafter at Arosa, Switzerland.-Ed.
}

\section{Global Ozone}

2) Calculations using two-dimensional photochemical models predict that increasing atmospheric concentrations of trace-gases could have caused a small decrease in ozone globally between 1969 and 1986. Predicted decreases between 30 and 60 degrees latitude in the northern hemisphere for this period ranged from 0.5 to $1.0 \%$ in summer, and 0.8 to $2.0 \%$ in winter, with the range reflecting the results from most models.

3) Analysis of data from ground-based Dobson instruments, after allowing for the effects of natural geophysical variability (solar cycle and quasi-biennial oscillations), shows measurable decreases from 1969 to 1986 in the annual average of total-column ozone, ranging from 1.7 to $3.0 \%$ at latitudes between 30 and 80 degrees in the northern hemisphere. The decreases are most pronounced, and ranged from 2.3 to $6.2 \%$, during the winter months (averaged for December through March, both inclusive). Dobson data are not adequate to determine total-column ozone changes in the tropics, subtropics, or southern hemisphere outside Antartica.

4) The model calculations are broadly consistent with the observed changes in column ozone, except that the mean values of the observed decreases at mid- and highlatitudes in winter are larger than the mean values of the predicted decreases. The observed changes may be due, wholly or in part, to the increased atmospheric abundance of trace-gases-primarily chlorofluorocarbons (CFCs).

5) Satellite instruments on Nimbus 7 (Solar Backscattered Ultraviolet [SBUV] and Total Ozone Mapping Spectrometer [TOMS] have provided continuous global records of total-column ozone since October 1978. Unfortunately they suffer from instrumental degradation of the diffuser plate, the rate of which cannot be uniquely determined. Thus the satellite data archived as of 1987 cannot be used alone to derive reliable trends in global ozone.

6) The SBUV and TOMS satellite data have been normalized by comparison with nearly coincident groundbased Dobson measurements in the northern hemisphere. The resulting column ozone data, averaged between 53 degrees South and 53 degrees North latitudes, show a decrease of about $2.5 \%$ from October 1978 to October 1985. This period is approximately coincident with the decrease in solar activity from the maximum to the minimum in the sunspot cycle.

7) Theoretical calculations predict that the total-column ozone would decrease from solar maximum to solar minimum by an amount varying between 0.7 and $2 \%$, depending upon the model assumed for solar ultraviolet variability. Thus, the observed decrease in ozone from the satellite data between late 1978 and late 1985 is predicted to have a significant contribution from the decrease in solar activity during this period.

8) Theoretical calculations predict that local ozone concentrations near $40 \mathrm{~km}$ altitude should have decreased [Concluded on page 92] 
segment of the continent which is referred to by scientists as the 'Maritime Antarctic'.

The 13 chapters of the book fall into 5 sections, which could be termed 'Preliminaries', 'Grahamland', 'Falkland Islands', 'Northern Islands', and 'Reflections'. These followed the sequence of the Author's voyage on the British RRS John Biscoe. The Preliminaries chapters give some of the background statistics of the Antarctic continent, about its size, massive quantities of ice, and extraordinarily cold temperature (would any account of Antarctica be complete without such statistics?). After some brief bibliographical data about himself (childhood recollections, school, university, first jobs), we read of the Author's life as an MEP and of the questions that he asked there about the EEC's policy towards Antarctica. How to arrange a 'jolly' of this sort, the costings, the journey to Punta Arenas in the south of Chile, and the organization of life aboard ship, occupy the majority of the preliminary chapters.

The Antarctic Peninsula (Grahamland) has two British bases, Rothera (largely devoted to the earth sciences) and Faraday (similarly devoted to the atmospheric sciences). These each feature in a chapter, containing long reports of discussions with scientists and base-staff, and descriptions of the scenery. After the Grahamland visit, the RRS John Biscoe visited the Falkland Islands, and again the Author devotes a chapter to these Islands as well as a chapter to the biological production of the Southern Ocean. The northern isles featured in the next section are the South Orkney Islands (the British base on Signy Island is devoted to the biological sciences) and South Georgia, where the small base on Bird Island is also concerned with biological research. It is in this section of the book that one gets the Author's most intimate glimpses of Antarctic wildlife: 'I spent a long time that afternoon just standing and watching... it could well be that I shall never again visit a penguin colony like this, never experience Nature in this super- abundant mood where penguins and seals and skuas and petrels have free run of sea and earth and sky, and Man, if he is there at all... is a tiny and insignificant spectator. None of these animals showed any fear of Man; none of the birds stepped aside to let me pass. On the contrary, as far as they were concerned, I was just another penguin, expected to respect the rules of the rookery like anyone else.' I perhaps felt nostalgic in reading these sentiments, since it is only after living a while in Antarctica that the visitor realizes that he has been privileged to experience one of the only, and maybe the only major, wilderness areas left on this planet.

The Author's reflections concentrate most on the Antarctic environment. He poses many questions that relate to the economics, and even the ethics, of setting aside a real wilderness area. He explores, perhaps not with scientific rigour, aspects of whale harvesting and the development of an offshore oil industry. He mentions the possibility of exploiting the mineral wealth of the continent and of opening the continent to tourism. But, ultimately, he sees conservation as being important, and he has a dream of a 'world park'. Almost the last words in the book are a personal statement 'My own belief is that there is no need now-and there will never be a need-to develop and exploit Antarctica'.

The appeal in this book is undoubtedly towards the interested public rather than to the scientific reader. I regret, however, that the interest to the public has not been stimulated more by a series of illustrations of the Antarctic's wildlife and of Antarctica's superb scenery.

MICHAEL B. USHER, Reader
Department of Biology
University of York
York YO1 $5 D D$,
England, UK.

between 1979 and 1985 by 5 to $12 \%$ in response to the decrease in solar ultraviolet output and the increased atmospheric abundance of trace-gases. This range represents the decreases predicted from different models for the latitude belt $30^{\circ}$ to $60^{\circ} \mathrm{N}$ for all seasons.

9) Analyses of satellite (Stratospheric Aerosol and Gas Experiment [SAGE]) and ground-based (Umkehr) data taken since 1979 show small decreases in ozone concentrations; these decreases peak near $40 \mathrm{~km}$ altitude, with mean values of 3 and $9 \%$, respectively. These observational values agree within the range of their error.

10) Stratospheric temperatures between 45 and $55 \mathrm{~km}$ altitude have decreased globally by about $1.7 \mathrm{~K}$ since 1979 , consistent with decreases in upper stratospheric ozone of less than $10 \%$.

\section{Antarctic Ozone}

11) There has been a large, sudden, and unexpected, decrease in the abundance of spring-time Antarctic ozone over the last decade. Ozone decreases of more than $50 \%$ in the total column, and $95 \%$ locally between 15 and $20 \mathrm{~km}$ altitudes, have been observed.
12) The total column of ozone in the austral spring of 1987 , at all latitudes south of 60 degrees south, was the lowest since pertinent measurements began there 30 years ago.

13) In 1987, a region of low-column ozone over Antarctica persisted until late November-early December, which is the longest since the region of stratospheric ozone depletion was first detected.

14) While the column ozone depletion is largest in the Antarctic spring-time, ozone appears to have decreased since 1979 by $5 \%$ or more at all latitudes south of $60^{\circ}$ south throughout the year.

15) The unique meteorology during winter and spring over Antarctica sets up the special conditions of an isolated air-mass (polar vortex) with cold temperatures required for the observed perturbed chemical composition.

16) The weight of evidence strongly indicates that Manmade chlorine species are primarily responsible for the observed decrease in ozone within the polar vortex.

Global Ozone Observing System World Meteorological Organization 41 Avenue Giuseppe-Motta 1211 Geneva 10. Switzerland. 